\title{
ERGONOMIA E ENFERMAGEM
}

\author{
Neusa Maria Costa Alexandre** \\ Emflia Luigia Saporiti Angerami*
}

ALEXANDRE, N. M. C. \& ANGERAMI, E. L. S. Ergonomia e enfermagem. Rev.Esc.Enf.USP São Paulo, 23(2): - , ago. 1989.

Este trabalho tem o objetivo de apresentar informaçōes fundamentais sobre Ergonomia. Faz também consideraçôes sobre a relevante contribuiçâo que pesquisas neste campo poderāo trazer ao trabalho da enfermagem.

UNITERMOS: Ergonomia. Enfermagem.

\section{INTRODUÇĀO}

Desde o início de nossa vida profissional, começamos a refletir sobre as péssimas condiçōes de trabalho a que estāo submetidos os profissionais de entermagem.

Procurando subsidios para este assunto, verificamos que a WORLD HEALTH ORGANIZATION"2, em publicação denominada "Occupational hazards in hospitals", menciona que tradicionalmente, os hospitais nāo têm sido considerados, quanto ao grau de risco à saúde, igual às indústrias pesadas tais como mineração, construção e manufatura. Consequentemente, menos atenção tem sido dispensada ao estudo das populaçōes hospitalares. Este mesmo artigo discute tópicos tais como problemas ergonômicos, acidentes de trabalho, turnos de trabalho, "stress", exposição a fatores físicos e a substâncias químicas.

NURSES ACTION GROUP ${ }^{17}$, em um artigo na revista Nursing Mirror, coloca que o pessoal de enfermagem é possivelmente o grupo mais negligenciado. Cita ainda que os riscos a que estāo submetidos são inumeráveis e frequentemente irreconheciveis.

En 1960 a ORGANIZAÇĀO INTERNACIONAL DO TRABALHO ${ }^{18}$ publicou um estudo sobre os problemas relativos às condições de vida e de trabalho do pessoal de enfermagem, no qual analisa principalmente questōes relativas à remuneraçāo, horas de trabalho, proteção à saúde, segurança social e oportunidades de fazer carreira, entre outros.

* Enfermeira Professora Assistente do Departamento de Enfermagem da Faculdade de Ciências Médicas da UNICAMP.

** Enfermeira Professora Titular do Departamento de Enfermagem Geral e Especializada da Escola de Enfermagem de Rıbeirão Preto da USP. 
Segundo CARVALHO ${ }^{2}$, em quase todos os países do mundo as condiçōes de trabalho do pessoal de enfermagem não são satisfatórias. Este autor relata ainda que a carência de profissionais, tanto do ponto de vista quantitativo como qualitativo, decorre de fatores diversos, entre os quais cita: remuneração inadequada, horário de trabalho muito longo sem período de descanso, plantões em domingos feriados sem a justa compensação, períodos incômodos ou fatigantes de trabalho (como os turnos da tarde e da noite) também sem a devida compensaçāo, e a quase impossibilidade de ascenção na carreira.

Atualmente, sabemos que o pessoal de enfermagem está exposto a múltiplos riscos. Entre estes, poderíamos citar a exposição a produtos químicos tóxicos, tensāo psicológica, fadiga e lombalgia.

MAURO $^{15}$ comenta que a enfermagem é uma das profissōes que contribuem para preservar a vida e a saúde do homem, mas ainda nảo conseguiu resolver os problemas relativos à sua própria proteção, estando sujeita à excessiva carga de trabalho e fadiga mais ou menos crônica. Neste mesmo artigo, a autora recomenda que seja difundido entre os enfermeiros o estudo de aspectos ergonômicos e de higiene e segurança do trabalho, visando a sua própria proteção.

Ponderando sobre estes dados e considerando a relevante contribuição que as pesquisás neste campo poderāo trazer a entermagem, apresentaremos neste trabalho uma síntese dos conceitos fundamentais da ergonomia os quais podem ser elementos de estímulo e reflexão para os enfermeiros.

\section{CONSIDERAÇÕES SOBRE ERGONOMIA}

Segundo MARCELIN \& FERREIRA ${ }^{14}$, o termo Ergonomia, de origem grega, (ergon = trabalho; nomos = lei, regra), foi adotado oficialmente em 1949 por ocasiāo da criaçāo da primeira Sociedade de Ergonomia, a "Ergonomia Research Society", por um grupo de psicúlogos, fisiologistas e engenheiros ingleses, interessados nos problemas de adaptação do trabalho ao homem.

Em 1972, SINGLETON ${ }^{20}$, numa publicaçāo da Organização Mundial da Saúde, define a Ergonomia como uma "tecnologia da concepção do trabalho baseada nas ciências biológicas humanas". PALMER 19 á a define como o "estudo cientifico da relaçāo entre o homem e seu ambiente de trabalho". Nesse sentido, o termo ambiente abrange não apenas o meio propriamente dito em que o homem trabalha, mas também os instrumentos, os métodos e a organização desse trabalho. Em relação com tudo isso está ainda a natureza do próprio homem, o que inclui suas habilidades, capacidades e limitaçōes.

Para GRANDJEAN" a Ergonomia é o "estudo do comportamento do homem em relaçāo ao seu trabalho". LAVILLE ${ }^{12}$ define-a como sendo "o conjunto de conhecimentos a respeito do desempenho do homem em atividade, a fim de aplicá-los à concepção das tarefas, dos instrumentos, das máquinas e dos sistemas 
de produçāo" e ASSAF' como "o estudo científico da adaptaçāo dos instrumentos, condiçōes e ambiente de trabalho às capacidades psicofisiológicas, antropométricas e biomecânicas do homem".

MALUF ${ }^{13}$ reconhece que há dificuldades para se definir Ėrgonomia e propöe a seguinte concepçäo altemativa: "ciência pragmática cujo objetivo é investigar, promover, restaurar ou implementar as condições de compatibilizaçăo entre as características artificiais de trabalho e de habitabilidade e as características evolutivas do ser humano".

Encontramos ainda outras detiniçōes ${ }^{3,4,9,10}$ mas observamos que todas apontam o ser humano como seu objetivo central.

Segundo SINGLETON ${ }^{20}$, foi a Segunda Guerra Mundial que estimulou o desenvolvimento da Ergonomia como uma disciplina essencial, integrada e sistemática. Durante a Segunda Guerra Mundial, a elevada frequência de acidentes veriticada no uso de determinados aparelhos preocupou os responsáveis. Foram então organizados equipes de médicos, psicólogos e engenheiros para que o desempenho destes aparelhos fosse examinado do ponto de vista anatômico, fisiológico e psicológico. Como consequência, muitos destes aparelhos foram redesenhados, adaptando-se melhor ao desempenho do organismo humano. Terminada a guerra, estes especialistas tornaram a se reunir em 1949, na Inglaterra, quando ficou patente que estavam diante de uma nova ciência de aplicação.

No após guerra, a Ergonomia se voltou para os setores produtivos não bélicos. Aí sua aplicação teve dois objetivos básicos: um, a nível ideológico, representa a preocupação dos dirigentes da sociedade com as condiçōes de trabalho; outro, a nível produtivo, representa a busca do aperfeiçoamento dos métodos de trabalho, respeitando determinadas condiçōes de conforto do trabalhador, visando o aumento da produtividade 5

Os estudos a esse respeito tiveram um aprofundamento ainda maior com o início dos programas espaciais e de segurança de veículos automotores.

Nas duas décadas subsequentes houve uma expansão considerável dessa ciência em diversos países sendo conhecida na Europa por Ergonomia e nos Estados Unidos por Engenharia Humana. MIRANDA ${ }^{16}$ relata que ela é também conhecida por Biomecânica, Biotecnologia, Engenharia Psicológica e Engenharia dos Fatores Humanos. SINGLETON ${ }^{20}$ ressalta que, independentemente do nome por que seja conhecida, tem como premissa básica: o mais importante fator no projeto de trabalho é o trabalhador.

Segundo WIERZBICKI ${ }^{23}$ a Ergonomia baseia-se em conhecimentos apresentados em outras ciências e especializaçōes tecnológicas tais como: Fisiologia, Anatomia, Engenharia, Cibernética e Biônica, entre outras. 
GRANDJEAN ${ }^{7}$ relata que no passado ela serviu principalmente para aumentar a produtividade mas que alguns dos seus objetivos atuais sāo:

- adaptar as demandas do trabalho à eficiência do homem para diminuir o "stress";

- desenhar máquinas, equipamentos e instalações de modo que possam ser operados com grande eficiência e segurança;

- estudar as proporçōes e condiçōes do local de trabalho para assegurar uma postura corporal correta;

- adaptar a iluminaçāo, a ventilação, o ruído, etc, às necessidades físicas do homem. Este autor lembra ainda que o seu propósito principal é contribuir para a satisfaçāo das necessidades humanas no ambiente de trabalho, incluindo a promoção de saúde e bem-estar.

SUWANABUN ${ }^{21}$ comenta que a pesquisa ergonômica deve cobrir três áreas principais:

- equipamentos e máquinas de modo que possam ser usados eficientemente, com o mínimo de "stress" e o máximo de segurança;

- o ambiente no qual o trabalho é realizado, incluindo ruído, vibração, temperatura, umidade e iluminação;

- a organização do trabalho, a qual demanda o uso de métodos biológicos de avaliar o trabalho, a distribuição de períodos de trabalho e repouso e a organização de linhas de produção e turnos de trabalho.

Quanto a uma classificaçāo da Ergonomia, $\operatorname{ASSAF}^{1}$ a divide em três tipos: 1) Ergonomia de concepção: é o estudo ergonômico de instrumentos e ambiente de trabalho antes de sua construção; 2) Ergonomia corretiva: é a que modifica sistemas já existentes; 3) Ergonomia seletiva: é feita selecionando-se o homem ideal e/ou a faixa de utilizadores ideal para uma máquina, atividade ou ambiente de trabalho já existentes.

LAVILLE $^{12}$ salienta que outras diferenciaçōes são ainda estabelecidas: Ergonomia dos meios de produçāo, isto é, dos componentes de trabalho, e Ergonomia do produto. No último caso, trata-se de conceber o objeto fabricado considerando os dados ergonômicos correspondentes ao número de consumidores. Este mesmo autor distingue ainda uma Ergonomia de proteção do homem que trabalha, para evitar o cansaço, a velhice precoce, os acidentes, etc., e, uma Ergonomia de desenvolvimento, que permitirá a concepção de tarefas de forma a elevar a capacidade e a competência dos operadores.

Entre os trabalhos realizados atualmente, poderíamos citar como exemplo: a avaliação da carga de trabalho por indicadores físiológicos; estudo sobre posturas e lombalgias profissionais; estudos antropométricos; trabalho em turnos e ritmos biológicos; estudos de postos específicos; trabalho em painéis de comando e computadores; estudos sobre envelhecimento e trabalho de mulheres.

No Brasil, a Ergonomia está apenas no início sendo segundo MIRANDA ${ }^{16}$, na América Latina, o primeiro país a implantar esta conquista tecnológica. $\mathrm{KEHL}^{11}$ cita algumas empresas estatais e privadas brasileiras que já estão se utili- 
zando dessa nova ciência. Em relação ao ensino, esse assunto está incluído em alguns currículos de cursos de Engenharia, Arquitetura, Desenho Industrial, Medicina e Enfermagem. Comentando sobre o papel da Ergonomia dentro da Medicina do Trabalho, GRANDJEAN ${ }^{8}$ assinala que esta é um valioso instrumento de prevençāo, uma vez que nāo somente revela precocemente um risco de doença, mas também desenvolve e propōe os meios necessários para assegurar o bem-estar do trabalhador.

Observamos que a Ergonomia sofreu um grande crescimento, diversificandose bastante quanto a objetivos e métodos de aplicaçāo em todo o mundo.

Para a FUNDAÇÃO GETÚlIO VARGAS ${ }^{6}$, a questão da busca de condiçōes de trabalho mais seguras e a consequente eliminaçāo das fontes de risco configura-se como caminho mais viável e adequado para a aplicação da Ergonomia em nosso país. Este centro ressalta, ainda, que o compromisso fundamental da Ergonomia tem que ser com o homem que trabalha, com a defesa de sua integridade e sua preservação frente às agressōes decorrentes da incompatibilidade entre o seu meio de trabalho e sua vida. Desse modo, um dos pontos básicos para atingir esses objetivos é a realização de uma análise cuidadosa do trabalho, voltada para a identificaçāo dos fatores de incompatibilidade no contexto de trabalho e suas consequências para o indivíduo. Ao analisar de forma crítica e metodológica as situações de trabalho, a Ergonomia visa reorganizá-las de modo que se possa eliminar fontes de prejuízo fisiológico, ou seja, eliminar aqueles elementos agressores que podem levar à perda parcial ou total de qualquer função vital a curto, médio ou longo prazo.

\section{CONSIDERAÇÕES FINAIS}

Através destes estudos, constatamos o quanto será valiosa a aplicação da Ergonomia na Enfermagem.

Atualizando conhecimentos ergonômicos, devemos urgentemente realizar pesquisas no sentido de avaliar a carga física do trabalho do pessoal de enfermagem, elaborar estudos sobre posturas, analisar o trabalho noturno, o trabalho em turnos, a duração da jornada de trabalho e os efeitos das perturbaçōes do ritmo biológico e investigar o ambiente no qual o trabalho é realizado, incluindo a iluminação, temperatura, ventilação e umidade.

Acreditamos que, conquistando condiçōes dignas de vida e de trabalho para o nosso pessoal, proporcionaremos uma melhor assitência de enfermagem aos nossos clientes.

ALEXANDRE, N. M. C. \& ANGERAMI, E. L. S. Ergonomic and nursing. Rev.Esc.Enf.USP, São Paulo, 23(2): - , Aug. 1989.

The aim of this paper is to present basic information on Ergonomics. It also emphasizes the important contribuitions of ergonomics researchs in nursing.

UNITERMS: Ergonomics. Nursing. 


\section{REFERÊNCIAS BIBLIOGRÁFICAS}

1. ASSAF, D. L. Ergonomia. In: SAAD, E. G. Introduçāo de engenharia de segurança no trabatho. São Paulo, FÚNDACENTRO, 1981. p.459-77.

2. CARVAlho, A. C. Condiçס̃es de trabalho do pessoal de enfermagem. Rev Bras.Enf., Brasflia, 30(2):157-161, abr./jun. 1977.

3. DE CICCO, F. M. G. A posiçâo da ergonomia na ciência e na industria. Rev. bras. Saúde Ocupac., São Paulo, 5(20):68-72, out/dez 1977.

4. ERGONOMIA: a ciência que torna o trabalho mais suave e seguro para o homem. Ind.e Prodt., Rio de Janeiro, 7(74):5-6, 1974.

5. FUNDAÇĀO GETÚLIO VARGAS. INSTITUTO DE SELEÇÃO E ORIENTAÇÃO PROFISSIONAL. CENTRO BRASILEIRO DE ERGONOMIA E CIBERNÉTICA. Otimização ergonơmica nos tratos culturais da lavoura de cana-de-af́úcar. Rio de Janeiro, 1980.

6. FUNDAÇĀO GETÚLIO VARGAS. INSTITUTO SUPERIOR DE ESTUDOS E PESQUISAS PSICOSSOCIAIS. CENTRO BRASILEIRO DE ERGONOMIA E CIBERNÉTICA. Análise sociotecnologica. Rio de Janeiro, 1982.

7. GRANDJEAN, E. Fitting the task to the man: an ergonomic approach. $3 \mathrm{ed}$. London, Taylor \& Francis, 1981.

8. GRANDJEAN, E. O papel da ergonomia na medicina do trabalho. Rev. bras. Saúde Ocupac., São Paulo, 8(32):31-6, out/dez. 1980.

9. ILDA, I. \& WIERZBICKI, H. A. J. Ergonomia. 3 ed. Săo Paulo, Ivan Rossi, 1978.

10. KARVONEN, M. I. Ergonomia criteria for occupational and public health surveys. Ergonomics, London, 22(6):641-50, Jun. 1979.

11. KHEL, S. A. P. Ergonomia: quando homem e máquina se afinam. Rev.Bras.Tecnol., Brasilia, 13(4):23-7, ago/set. 1982 .

12. LAVILle, A. Ergonomia. Såo Paulo, E.P.U., 1977.

13 .MALUF, V. M. M. Uma concepçăo evolucionista da ergonomia. Rev. bras. Saúde Ocupac., Såo Paulo, 8(29):22-32, jan/mar. 1980.

14. MARCELIN, J. \& FERREIRA, L. L. Orientaçöes atuais da metodologia ergonômica na França. Rev.bras. Saúde Ocupac., São Paulo, 10(37):64-9, jan/mar. 1982.

15. MAURO, M. Y. C. et alii Fadiga e aspectos ergonómicos no trabalho de enfermagem. Rev Bras.Eaf., Brasília, 29(4):7-18, 1976.

16. MIRANDA, I. K. A ergonomia no sistema organizacional ferroviário. Rev. bras. Saúde $O$. cupac., São Paulo, 8(29):63-70, jan/mar. 1980.

17. NURSES ACTION GROUP. Safe as hospitals? Nurs.Mirror, Sussex 152(5):20-2 Jan. 1981.

18. ORGANIZAÇĀO INTERNACIONAL DO TRABALHO Emploi et conditions de travail du personel infirmier. Geneve, Imprimerie Centrale, 1960.

19. PALMER, C. Ergonomia. Rio de Janeiro. Fundaçāo Getúlio Vargas, 1976.

20. SINGLETON, W. T. Introduction to ergonomics. Geneva, World Health Organization, 1972.

21. SUWANABUM, M. Ergonomics as some medical implications. J.Med.Assoc.Thai., Bangkok 55(8):474-7, Aug. 1972.

22. WORLD HEALTH ORGANIZATION. Occupational hazards in hospitals. Copenhagen, Regional Office for Europa, 1983. 68 p. (EURO. Reports and Studies, 80).

23. WIERZBICKl, H. A. J. Ergonomia: adaptação do trabalho ao homem. Rev. bras. Saúde Ocupac., Sāo Paulo, I(3):20-6, jul/set. 1973. 